\title{
The Effect of Regional Industrial Restructuring on the Resource Environmental Carrying Capacity in Jingjiang City, Jiangsu Province, China
}

\author{
Yunlong Bi, ${ }^{1,2}$ Yi Hu, ${ }^{3,4}$ Xiaoli $\mathrm{Xu}^{2}$ and Fangqu Niu $\mathbb{i D}^{5}$ \\ ${ }^{1}$ School of Earth Sciences and Resources, China University of Geosciences, Beijing 100083, China \\ ${ }^{2}$ Consulting \& Research Center Ministry of Natural Resources, Beijing 100035, China \\ ${ }^{3}$ Changzhou City Planning and Design Institute, Changzhou 213000, China \\ ${ }^{4}$ College of Geography, Nanjing Normal University, Nanjing 210023, China \\ ${ }^{5}$ Institute of Geographic Sciences and Natural Resources Research, CAS, Beijing 100101, China \\ Correspondence should be addressed to Fangqu Niu; niufq@lreis.ac.cn
}

Received 15 May 2020; Revised 10 September 2020; Accepted 16 September 2020; Published 30 September 2020

Academic Editor: Jun Yang

Copyright (C) 2020 Yunlong Bi et al. This is an open access article distributed under the Creative Commons Attribution License, which permits unrestricted use, distribution, and reproduction in any medium, provided the original work is properly cited.

\begin{abstract}
Disordered industrial expansion in a given region leads to the excessive consumption of resources and environmental deterioration. Therefore, the influence of the regional industrial structure and layout on the resource environmental carrying capacity (RECC) is receiving attention. This study constructs a comprehensive analytical framework of the industries, population, the economy, resources, and the environment. This framework evaluates the importance of each industry with respect to regional socioeconomic development; furthermore, it classifies industries based on the evaluation results and assumes various development scenarios for industrial restructuring. Based on ArcGIS spatial analysis tool, this study analyzes the consumption of resources and the environment in each township under the current development scenario. In addition, this study provides basic support for the optimization of the industrial space layout. The RECC is assessed under different development scenarios, and the results provide a basis for industrial restructuring. The results show that the Jingcheng Subdistrict consumes the most resources and environment among all the township units. However, since it has the highest GDP, it consumes the least resources and the environment per unit GDP overall. The results also show that the RECC with the development of the petroleum, coking, and nuclear fuel processing products industry can maximize the RECC of Jingjiang. The analytical framework in this study effectively connects regional industrial restructuring to the RECC, which can enhance the operability of the decision support.
\end{abstract}

\section{Introduction}

The population explosion and the rapid progress of science and technology have considerably promoted industries qualitatively and quantitatively. Industrial expansion has shown a blind trend to meet human demands. In addition, problems caused by resource shortages, environmental pollution, and ecological damage have gradually emerged, along with an increasing emphasis on sustainable development. There has been considerable attention on the effects of regional industrial restructuring on the resource environmental carrying capacity (RECC) and the function of the resource environmental carrying capacity evaluation during the industrial layout and restructuring $[1,2]$.

The United States was early to study the game relationship between environmental protection and social and economic development. In the 1990s, Grossman and Krueger proposed the Environmental Kuznets curve (EKC) based on the Kuznets curve, in which they demonstrated the relationship between environmental quality and per capita income [3-5]. Other scholars have conducted case studies on the EKC from different perspectives. In some countries, research on this topic has been focused on the international and national macroscale, whereas research in China has 
explored the situation on the relatively small microscale. For example, while focusing on the macroscale, studies have focused on the establishment and application of a comprehensive evaluation indicator system for the RECC of city clusters and specific regions, such as provinces or cities and counties. Recently, research on the RECC has been diversified. However, its evaluation of specific areas has remained almost static, which reflects the utilization and surplus of a region's resources and environment. There is still a disconnection with reality.

This study considers Jingjiang City, Jiangsu Province, China, as the research object, and it starts by evaluating the importance of industries in social and economic development and it classifies them. Then, this study evaluates the existing industrial structures in Jingjiang City and it carries out theoretical optimization and upgrading. This simulates the maximum population and the economic scale of Jingjiang City under different industrial development scenarios, it corrects the direction of industrial restructuring, and it demonstrates the impact of industrial restructuring on the region's resources and environment loadability. In addition, this also includes the guiding role of the RECC evaluation in industrial restructuring. The analytical framework can be applied to other areas through parameter correction, and this can help promote theoretical research and the practical application of the RECC. It also provides a decision-making basis for realizing the maximum socioeconomic development scale under the condition of sustainable development.

\section{Theoretical Research}

2.1. Concept of Industrial Restructuring. The concept of industrial restructuring has two meanings. One is the optimization of an area's existing industrial structure. The industrial structure of this area has the ability to transform and adapt. It can adapt to changing market demands, and it yields the greatest benefits. The specific performance is a process in which the quantity proportion relation, the economic technology connection, and the interaction relation among industries tend to be coordinated and balanced. The other meaning is upgrading an area's existing industrial structure. Generally, the area's industrial structure is transformed from a lower form to a higher form. In other words, industrial restructuring generally follows the evolution law in which the industrial structure goes from a low level to a high level.

In 1672, William Petty compared the income characteristics of the agriculture, manufacturing, and service industries in his Political Arithmetic, which was an early study that involved industrial structure [6]. In 1940, Clark pointed out the general law of the industrial structure change that was based on a comparison of the labor input and the total output of three industries in more than 40 countries; this formed the basis of the modern industrial structure analysis [7]. In 1957, Simon, putting forward the Kuznets fact, demonstrated the law of industrial structure change by analyzing the proportion of the labor force and the national income in three industries [8].
Recently, the extensive research on industrial restructuring has generated in-depth discussions on the influence of industrial structure on economic development and growth, the influencing factors of industrial structure changes (changes in preferences, differences in the technological progress rates, economic openness and industrial transfer, and the rise of the global service industry), and the internal optimization of a single industry. However, there is a lack of research on the sustainable impact of industrial restructuring on social and economic development, as well as the resource and environmental loadability in some areas [9].

\subsection{Concept of Resource Environmental Carrying Capacity.} With the increasing depth of research, the characterization of the RECC has been expanded to include many concepts, such as the land carrying capacity [10-13], the water resource carrying capacity [14-17], the mineral resource carrying capacity [18], the environmental carrying capacity [19-21], and the ecological carrying capacity [22-25]. It is generally understood as the maximum economic scale and population that can be carried by the resource endowment and the environmental capacity of a certain area under the premise that the natural environment of a region is not damaged and the ecosystem remains well balanced [26, 27].

Malthus was the first to study the effects of the environment's limitations on human material needs [28]. His paper titled, "An essay on the principle of population," was published in 1798 [29], and it was regarded as the most influential theory of population at that time. It was also the basis of the modern concept of the RECC [30], and it established the research framework of "population growthresources and environment-development" [31].

Errington put forward the concept of carrying capacity in 1934 and defined it as the maximum biomass of an ecosystem, which reaches saturation levels as a result of limited food and shelter. In addition, Errington stated that constraints coexist with predators and human exploitation. For example, Errington used the example of wild quail for evaluating the RECC that can support the largest populations of wild quail [32].

After that, related research on the carrying capacity gradually deepened to involve a variety of resources and environmental factors. Before the 1950s, research was focused on the resource carrying capacity, especially in the context of the upper limit of natural resources that allows the survival and development of the population (other organisms) in an area. From the 1960s to the 1970s, the restriction of environmental factors on human social and economic development was included in the study of the carrying capacity. In addition, the concept of relative balance gradually replaced the idea of the absolute ceiling. Since the 1990s, this topic has been developed from studying the constraints of a population's social and economic development to the effects of the resource consumption, environmental pollution, and ecological occupation, which were all caused by human activities, on the ecosystem's stability $[33,34]$. The research on RECC has gradually changed from the examination of the individual influential factors to 
comprehensive research on all types of factors $[35,36]$. Research methods have also been developed and have become an important basis for measuring the sustainable development of the population, resources, ecological environment, and economics in an area.

2.3. Correlation. It is beneficial to improve the resource and environmental loadability of an area so that industrial restructuring is environmentally friendly and it efficiently uses resources. The optimization or upgrading of an industrial structure not only considers the importance of a certain industry or group of industries in the social and economic development of an area, but it also takes into account natural ecological environmental factors, such as the resource endowment and the environmental capacity of an area [37]. Generally, industrial restructuring is likely to develop toward a larger output value, and theoretically, the regional resource and environmental loadability is improved in order to maximize profits. Industrial restructuring greatly affects the comprehensive evaluation indicator system of the RECC of a certain area.

The comprehensive consideration of the two-way influence is conducive to the establishment of a more objective evaluation system of RECC, which plays a supporting role in assisting industrial regulation and distribution. An objective evaluation system of the RECC enables the resource endowment and environmental capacity of a certain area to support industrial development within a sustainable range, which is of great significance for industrial restructuring in this area.

The correlation between these two factors means that they not only restrict but they also positively affect each other. This is an effective combination of theoretical research and a practical application [38]. A comprehensive assessment system of the RECC that includes industries, the population, the economy, social development, and the natural environment is established. This is conducive to a more objective assessment of the existing industrial structure in a certain area, and it plays a guiding role in the sustainable development of the area. Industrial optimization and upgrading may greatly increase the maximum population and economic scale that can be carried by constraints such as natural resources and the environmental capacity in a certain area. The combination of the two studies can promote the practical application of research on the RECC while also promoting scientific development for the industrial restructuring.

\section{Research Area and Methods}

\subsection{Research Area and Data}

(1) Research area: Jingjiang City is located in the southern plain of Jiangsu Province, China, $31^{\circ} 56^{\prime}-32^{\circ} 08^{\prime} \mathrm{N}$ latitude and $120^{\circ} 01^{\prime}-120^{\circ} 33^{\prime} \mathrm{E}$ longitude; Figure 1. The terrain of Jingjiang is flat, where Henggang is at the boundary with an elevation of 2.5-4.5 m, in which it is low in the south and high in the north. The east, south, and west of Jingjiang face the Yangtze River; Zhangjiagang, Jiangyin, and Wujin are located across the river from Jingjiang, and the northeast and northwest of Jingjiang are Rugao and Taixing, respectively. The Jinghu, Tongsan, and Ningtong expressways and the Xinchang railway pass through Jingjiang. It only takes about an hour and a half to travel to Jingjiang City from Shanghai, Nanjing, and other major international airports in eastern China. Jingjiang is located in the center of the Huning Yangtze River Channel, and it is an important transportation hub in the lower reaches of the Yangtze River.

Presently, the Yangtze River Delta integration national strategy has entered a new stage of progress, and it is breeding new drivers of China's economic transformation. Jingjiang is located in the core area of the Yangtze River Delta. Its extensive usage of resources and the environment has restricted the transformation of the economic development mode and hindered the rapid and stable development of the local social economy for a long time. Thus, Jingjiang City focuses on regional comparative advantages, industrial characteristics, and market potential, and it strengthens the research on the effect of regional industrial restructuring on the RECC. This has important guiding significance for alleviating the pressure of Jingjiang City's industrial development on the resources and environment, and it also provides reference for the "brother cities" in the Yangtze River Delta.

(2) Data source: the sources of data that were acquired in this study are as follows: China City Statistical Yearbook 2017, Taizhou City Water Resources Bulletin 2016, Jingjiang Statistical Yearbook 2016, Adjustment plan for the general plan for land use in Jingjiang City (2006-2020), and the survey data of industrial land use in Jingjiang City (2016). The industrial classification is based on the "Industrial classification for national economic activities" (GB/ t4754-2017).

3.2. Industrial Restructuring Evaluation Indicator System. According to the actual situation for Jingjiang, the industrial restructuring evaluation indicator system was constructed in this study on the basis of the scientific, systematic, comprehensive, comparable, and operable principles of the indicator selection and the contribution of industries to social and economic development. The indicators include industrial correlation indicators, industry scale indicators, and industry-level indicators. Industrial correlation indicators include the induction coefficient and the influence coefficient [39]. Industry scale indicators include the industrial market potential and the income elasticity of demand [40]. In addition, industry-level indicators include the economic benefit coefficient, the labor productivity indicator, the main business income ratio, and the average growth rate of the industrial added value [40]. The calculation is based on the input-output table of Jiangsu Province (2012). The 


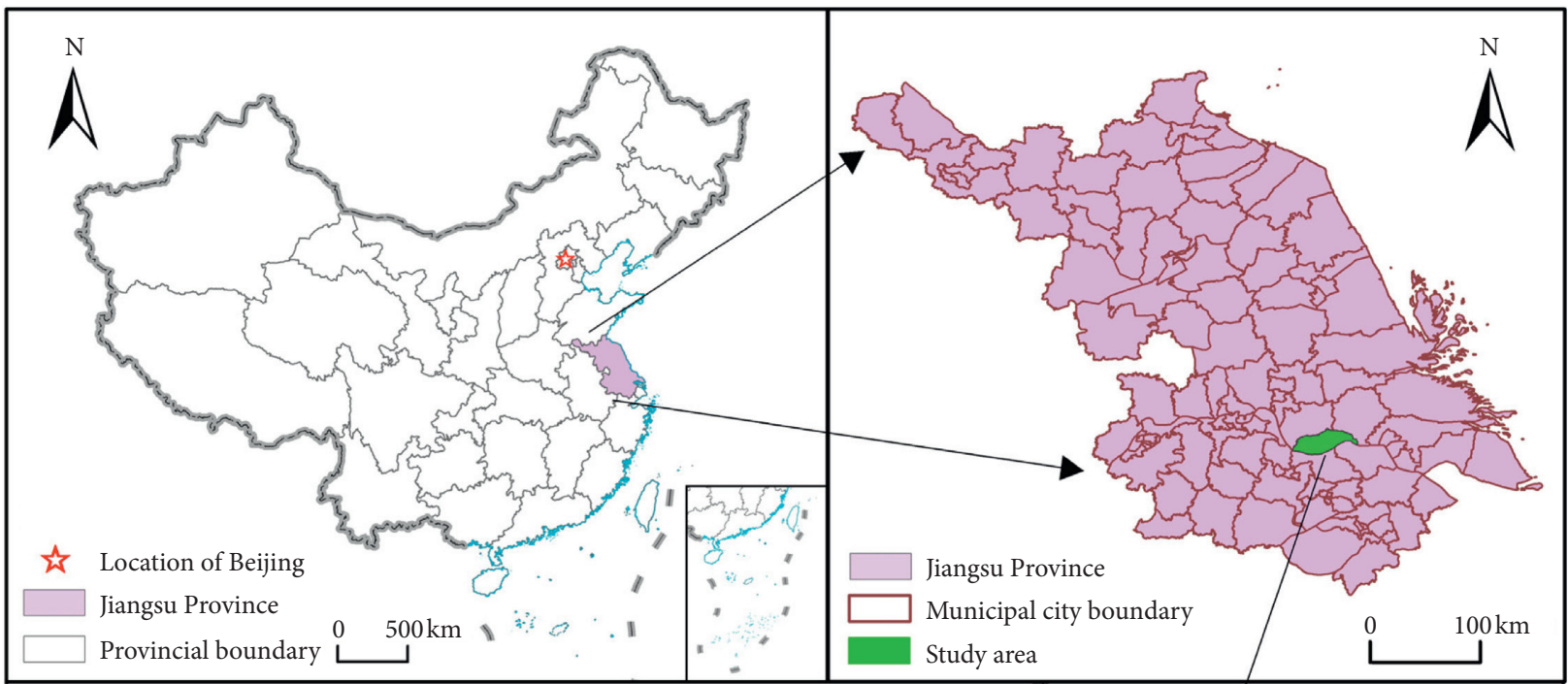

(a)

(b)

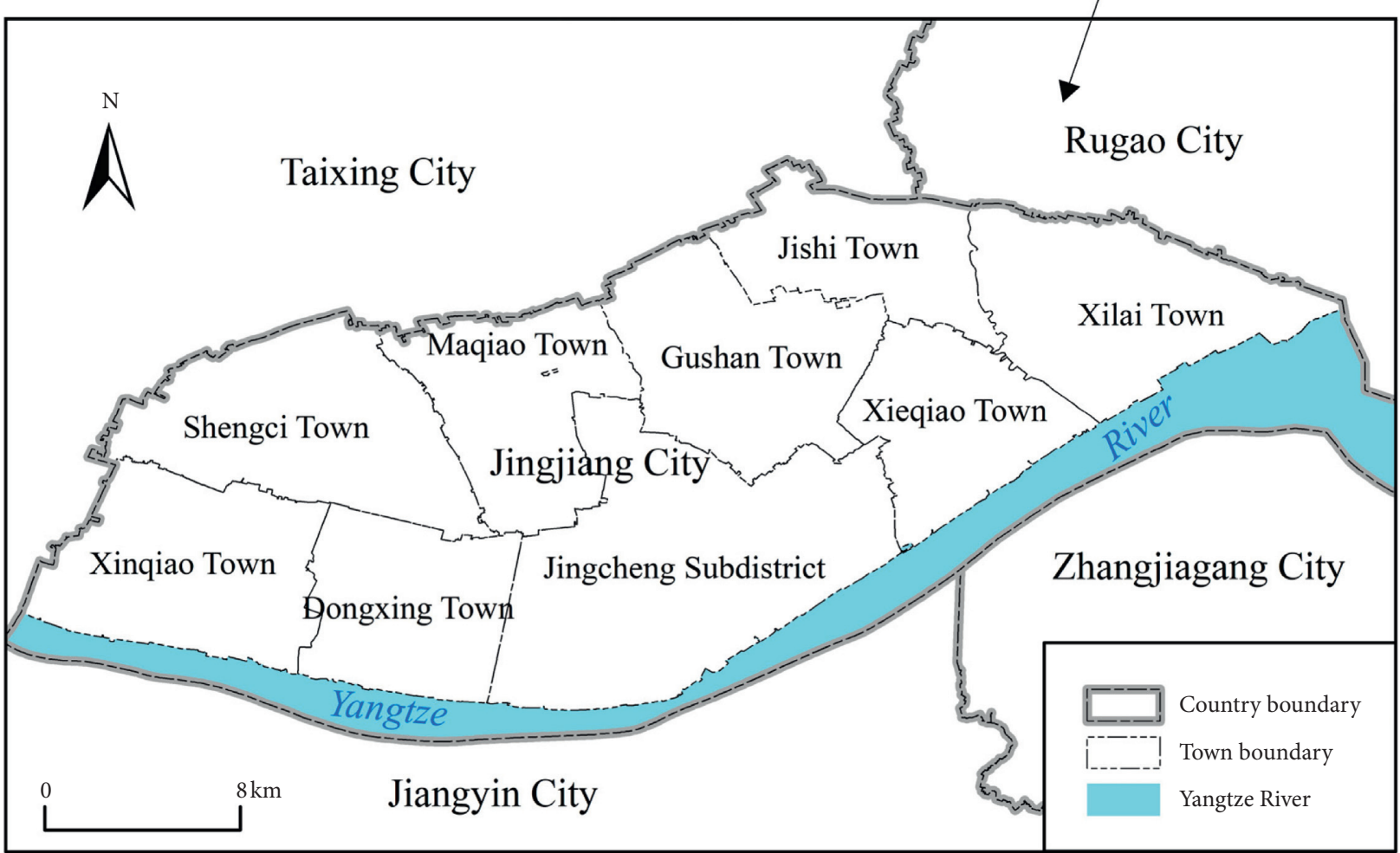

(c)

Figure 1: Study area: Jingjiang City, Jiangsu Province.

importance of the industries to the regional economic development was evaluated by using the weight value of each industrial indicator. This resulted in the division of the regional industries into leading industries, general industries, and industries to be eliminated.

(1) Industrial correlation indicators: these indicators are divided into the forward correlation and the backward correlation. They refer to the degree in which the change in any industrial demand directly or indirectly causes a change in the input and output of other industrial sectors. The induction coefficient and the influence coefficient are commonly used as industrial correlation indicators.

The induction coefficient $\left(u_{i}\right)$ can be calculated as follows:

$$
u_{i}=\frac{\sum_{j=1}^{n} b_{i j}}{1 / n \sum_{i=1}^{n} \sum_{j=1}^{n} b_{i j}},
$$

where $b_{i j}$ is the total input coefficient in the inputoutput analysis, $n$ is the number of industries, and $u_{i}$ is 
the induction coefficient of industry $i$. The size of $u_{i}$ reflects the impact of the increase in the output of each industry on the output of industry $i$, that is, the forward correlation degree of industry $i$. The higher the induction coefficient, the stronger the forward correlation ability. The induction coefficient of an industry at the average level is 1 . In addition, the induction coefficient of a leading industry should be greater than 1 . The influence coefficient $\left(v_{j}\right)$ can be calculated as follows:

$$
v_{j}=\frac{\sum_{i=1}^{n} b_{i j}}{1 / n \sum_{j=1}^{n} \sum_{i=1}^{n} b_{i j}},
$$

where $b_{i j}$ is the total input coefficient in the inputoutput analysis, $n$ is the number of industries, and $v_{j}$ is the influence coefficient of industry $j$. The size of $v_{j}$ reflects the impact of the increase in the output of industry $j$ on the output of the other industries, that is, the backward correlation degree of industry $j$. The higher the influence coefficient, the stronger the backward correlation ability. The induction coefficient and the influence coefficient of one industry will not be large at the same time. Generally, the induction coefficients of basic industries are large, and the influence coefficients of leading industries are large.

(2) Industry scale indicators: these indicators include the industrial market potential and the income elasticity of demand.

The industrial market potential can be used to evaluate the market potential of an industry based on a combination of local production and the market demand and provincial or national production and the market demand. The industrial market potential $\left(M_{j}\right)$ can be determined as follows:

$$
M_{j}=\frac{S_{j}^{r}}{S_{j}^{c}} \times \frac{a S_{j}^{r}}{a S_{j}^{c},} \quad j=1,2, \cdots, n,
$$

where $M_{j}$ is the market potential of industry $j$, and $S_{j}^{r}$ and $S_{j}^{c}$ are the annual sales volume of an industry in Jingjiang and the annual sales volume of the same industry in Jiangsu Province. $a S_{j}^{r}$ and $a S_{j}^{c}$ are the per capita annual sales of an industry in Jingjiang and the per capita annual sales of the same industry in Jiangsu Province, respectively.

The income elasticity of demand $\left(N_{i}\right)$ can be determined as follows:

$$
N_{i}=\frac{y}{x_{i}} \times \frac{\partial_{x_{i}}}{\partial_{y}}
$$

where $y$ is the national income and $x_{i}$ is the product demand of industry $i . N_{i}$ reflects the impact of the changes in the national income for the changes in the product demand of industry $i$. Generally, an industry with a large income elasticity of demand has a strong market expansion ability. When $N_{i}<1$, the demand expansion rate of industry $i$ 's demand is lower than the growth rate of the national income. When $N_{i}=1$, the growth rate of the industrial demand is average. When $N_{i}>1$, the demand expansion rate of industry $i$ 's demand is higher than the growth rate of the national income. The regional leading industry should be the industry with the greatest income elasticity of demand.

(3) Industry-level indicators include the economic benefit coefficient, the labor productivity indicator, the main business income ratio, and the average growth rate of the industrial added value.

The economic benefit coefficient $\left(E_{j}\right)$ can be calculated as follows:

$$
E_{j}=\frac{V_{j}}{X_{j}}, \quad j=1,2, \cdots, n,
$$

where $V_{j}$ is the growth that is generated by industry $j$ and $X_{j}$ is the total input of industry $j$.

The labor productivity indicator $\left(P_{j}\right)$ is calculated as follows:

$$
P_{j}=\frac{O_{j}}{Q_{j}}, \quad j=1,2, \cdots, n,
$$

where $O_{j}$ is the total output value of industry $j$ in industrial statistics and $Q_{j}$ is the average labor force of all industries in industrial statistics.

The main business income ratio $\left(L_{j}\right)$ is determined as follows:

$$
L_{j}=\frac{W_{j}}{X_{j}}, \quad j=1,2, \cdots, n,
$$

where $W_{j}$ is the main business income of industry $j$ in industrial statistics and $X_{j}$ is the main business income of all industries in industrial statistics.

In addition, this study uses the average growth rate of the industrial added value.

\subsection{Evaluation Methods}

\subsubsection{Industrial Importance Evaluation}

(1) Data Preprocessing. The data are preprocessed, and the maximum is computed before determining the weight. The maximum and minimum standardization method is adopted according to the positive and negative attributes of the indicators.

$$
\begin{aligned}
& \text { Positive indicators : } x_{i j}^{\prime}=\frac{x_{i j}-\min _{i j}}{\max _{i j}-\min _{i j}}, \\
& \text { Negative indicators : } x_{i j}^{\prime}=\frac{\max _{i j}-x_{i j}}{\max _{i j}-\min _{i j}},
\end{aligned}
$$


where $x_{i j}^{\prime}$ denotes the values after standardization, $x_{i j}$ is the original data of indicator $j$ of industry $i$, and $\max _{i j}$ and $\min _{i j}$, respectively, represent the maximum and minimum values of indicator $j$.

(2) Determination of the Weight and Industrial Importance. There are two methods to determine the weight of the indicators: the subjective weighting method and the objective weighting method. To avoid subjectivity in the weight assignment, the entropy method in the objective weighting method is adopted to determine the weight value of each indicator $[41,42]$. Then, the importance of each industry in Jingjiang is calculated. The importance of each industry $\left(V_{i}\right)$ is calculated as follows:

$$
V_{i}=\sum_{j=1}^{n} x_{i j} w_{j},
$$

where $x_{i j}$ is a value after standardization and $w_{j}$ is the weight value of each indicator.

Jingjiang is a developed city, and this investigation focuses on the analysis of 18 industries that have a significant impact on its social and economic development. The evaluation results are presented in Table 1. Industries are ranked and divided into three categories according to the natural breaks. The first category is the leading industries, which are important industries that affect Jingjiang's social and economic development and the focus of industrial structure optimization. The second one is general industries, which occupy a certain proportion in the social and economic development of Jingjiang, and they represent industries that continue to develop over a certain duration. The third is industries that will be eliminated; these industries do not adapt to Jingjiang's social and economic development, and they should be reduced or eliminated in industrial restructuring.

\subsubsection{Socioeconomic Resources and Environmental Effects.} The purpose of analyzing socioeconomic resources and the environmental effects is to determine the resource availability and to analyze the consumption intensity of resources and the environment by major industries and the existing population in Jingjiang. This is performed to identify the impact of industrial restructuring on the RECC.

In this study, the resource availability includes land resource availability, water resource availability, and the water environmental capacity.

Land resource availability: according to the adjustment plan for the general plan for land use in Jingjiang City (2006-2020), in 2020, the planned construction land in Jingjiang will be $18,466.77 \mathrm{hm}^{2}$, the used construction land will be $17,562.97 \mathrm{hm}^{2}$, and the remaining construction land will be $883.80 \mathrm{hm}^{2}$, which can be used to support the growth of the population and the economic scale.

Water resource availability: according to Taizhou City Water Resources Bulletin 2016, in 2016, the total amount of available water resources in Jingjiang city was 730 million $\cdot \mathrm{m}^{3}$, the total water consumption was 286.2 million $\cdot \mathrm{m}^{3}$, and there were 443.8 million $\cdot \mathrm{m}^{3}$ of remaining water resources, which can be used to support the growth of the population and the economic scale.

Water environmental capacity: the chemical oxygen demand (COD), which is the main pollutant in water, is used to measure the water environment in this study. In 2016, the total COD emission in Jingjiang was 7,272.60 tons. According to the environmental quality standards for surface water in China [43], the COD of Class I and Class II water is less than $15 \mathrm{mg} / \mathrm{L}$. The calculation method of the water environmental capacity $(R)$ is as follows:

$$
R=W_{t} \times S-E_{\mathrm{COD}}
$$

where $W_{t}$ is the total amount of available water resources in Jingjiang, ECOD is the emission of COD, and $S$ is the water quality standard of COD, which is $15 \mathrm{mg} / \mathrm{L}$. The calculated remaining water environmental capacity is 3677.4 tons, which can be used to support the population and economic growth.

Industrial resources and environmental effects: the intensity of the resource and environment consumption is calculated for each industry (Table 2). Under the scenario of industry restructuring, the number of industries will remain unchanged for a period of time in the future.

Population resources and environmental effects: the population will also consume resources and impact the environment. According to the discussion mentioned above and the relevant data, the per capita residential land (i.e., the consumption of construction land) in Jingjiang is $61.88 \mathrm{~m}^{2}$, and the per capita domestic water consumption is $46.41 \mathrm{~m}^{3}$. The annual living discharge of COD per capita is $16.60 \mathrm{~kg}$.

3.3.3. RECC Evaluation. Further industrial development requires the consumption of resources, and so does the growing population. The sum of the industrial development and the population consumption is equal to the available amount of a given resource when the resource has reached the maximum carrying capacity under the condition that the existing social and economic factors are invariable. The calculation is as follows:

$$
\begin{aligned}
A & =\sum_{i=1}^{m} P_{i} \times \operatorname{con} A_{i}+\text { Pop } A, \\
\text { pop } & =\frac{\sum_{i=1}^{m} P_{i}}{a \mathrm{GDP}},
\end{aligned}
$$

where $A$ is the availability or capacity of a given resource, $m$ is the number of industries, $P_{i}$ is the output value of industry $i$, con $A_{i}$ is the consumption intensity by industry $i$ of resource or the environmental capacity, pop is Jingjiang's 
Table 1: Weights of the industries in Jinjiang City, Jiangsu Province.

\begin{tabular}{|c|c|c|c|}
\hline Categories & Industries & Value & Rank \\
\hline \multirow{3}{*}{ First category (leading industries) } & Electricity, heat production, and supply industry & 0.6831 & 1 \\
\hline & Metal smelting and rolling products & 0.4282 & 2 \\
\hline & Transport and communication facilities & 0.3051 & 3 \\
\hline \multirow{9}{*}{ Second category (general industries) } & Electrical machinery and equipment & 0.2425 & 4 \\
\hline & Food and tobacco & 0.2314 & 5 \\
\hline & Metal products & 0.2133 & 6 \\
\hline & General equipment & 0.2094 & 7 \\
\hline & Chemical products & 0.2042 & 8 \\
\hline & Instruments and apparatus & 0.1855 & 9 \\
\hline & Wood products and furniture & 0.1695 & 10 \\
\hline & Textile & 0.1671 & 11 \\
\hline & Petroleum, coking, and nuclear fuel processing products & 0.1504 & 12 \\
\hline \multirow{6}{*}{ Third category (industries to be eliminated) } & Communications, computers, and other electronic equipment & 0.1444 & 13 \\
\hline & Dedicated device & 0.1318 & 14 \\
\hline & Agricultural, forestry, animal husbandry and fishery products, and services & 0.1151 & 15 \\
\hline & Paper printing, stationery, and sporting goods & 0.1134 & 16 \\
\hline & Nonmetal mineral products & 0.0875 & 17 \\
\hline & Textile clothing, shoes, hats, leather, down, and its products & 0.0478 & 18 \\
\hline
\end{tabular}

TABLe 2: Resource and environmental consumption per unit of GDP by industries in Jinjiang City, Jiangsu Province.

\begin{tabular}{|c|c|c|c|c|}
\hline Categories & Industries & $\begin{array}{l}\text { Land resource } \\
\text { consumption per unit of } \\
\text { GDP }\left(\mathrm{hm}^{2} / 100 \text { million }\right)\end{array}$ & $\begin{array}{l}\text { Water resource } \\
\text { consumption per unit of } \\
\text { GDP }\left(\mathrm{m}^{3} / 10 \text { thousand }\right)\end{array}$ & $\begin{array}{c}\text { Water environment } \\
\text { consumption per unit of } \\
\text { GDP (COD) (kg/10 } \\
\text { thousand) }\end{array}$ \\
\hline \multirow{3}{*}{$\begin{array}{l}\text { First category } \\
\text { (leading } \\
\text { industries) }\end{array}$} & $\begin{array}{l}\text { Electricity, heat production, } \\
\text { and supply industry }\end{array}$ & 0.5004 & 1.2359 & 0.0037 \\
\hline & $\begin{array}{c}\text { Metal smelting and rolling } \\
\text { products }\end{array}$ & 1.4385 & 0.3799 & 0.0483 \\
\hline & $\begin{array}{l}\text { Transport and communication } \\
\text { facilities }\end{array}$ & 1.9605 & 0.9112 & 0.0511 \\
\hline \multirow{9}{*}{$\begin{array}{l}\text { Second category } \\
\text { (general } \\
\text { industries) }\end{array}$} & $\begin{array}{c}\text { Electrical machinery and } \\
\text { equipment }\end{array}$ & 1.5331 & 0.8738 & 0.0743 \\
\hline & Food and tobacco & 0.7927 & 0.8179 & 0.0440 \\
\hline & Metal products & 1.9241 & 0.7413 & 0.0784 \\
\hline & General equipment & 2.7738 & 0.6372 & 0.1556 \\
\hline & Chemical products & 1.2971 & 0.7632 & 0.0798 \\
\hline & Instruments and apparatus & 1.5396 & 0.5195 & 0.0361 \\
\hline & Wood products and furniture & 5.5781 & 0.4520 & 0.1225 \\
\hline & Textile & 1.5898 & 2.7765 & 0.0701 \\
\hline & $\begin{array}{l}\text { Petroleum, coking, and nuclear } \\
\text { fuel processing products }\end{array}$ & 0.3304 & 0.1415 & 0.0077 \\
\hline \multirow{7}{*}{$\begin{array}{l}\text { Third category } \\
\text { (industries to be } \\
\text { eliminated) }\end{array}$} & $\begin{array}{l}\text { Communications, computers, } \\
\text { and other electronic equipment }\end{array}$ & 3.7131 & 0.4868 & 0.0829 \\
\hline & Dedicated device & 3.6727 & 0.5806 & 0.1683 \\
\hline & Agricultural, forestry, animal & & & \\
\hline & $\begin{array}{l}\text { husbandry, and fishery } \\
\text { products and services }\end{array}$ & 0.7410 & 1.7741 & 0.0557 \\
\hline & $\begin{array}{l}\text { Paper printing, stationery, and } \\
\text { sporting goods }\end{array}$ & 9.9606 & 3.1165 & 0.8587 \\
\hline & Nonmetal mineral products & 1.4810 & 0.5820 & 0.0906 \\
\hline & $\begin{array}{l}\text { Textile clothing, shoes, hats, } \\
\text { leather, down, and its products }\end{array}$ & 3.2796 & 1.0608 & 0.2572 \\
\hline
\end{tabular}

population, and $\operatorname{Pop} A$ is the per capita consumption or the emissions by Jingjiang's population of resource or the environmental capacity. If $a$ GDP is the current GDP per capita of Jingjiang, then the maximum industrial development and the population supported by the land resource availability, water resource availability, and the water environmental capacity under the current conditions can be calculated. 


\section{Results}

4.1. Resource and Environment Consumption Status Analysis. According to the survey data of industrial land use in Jingjiang City (2016), the resource and environment consumption and the resource and environment consumption per unit of GDP in Jingjiang were analyzed based on ArcGIS spatial analysis tool, which includes land resources, water resources, and the water environment (Figure 2). The data of nine towns in Jingjiang were divided into four levels (high is the first level, medium is the second level, lower is the third level, and low is the fourth level) by natural breaks. Afterwards, they were analyzed in combination with the local industrial development model.

The results show that the Jingcheng Subdistrict has a high consumption of resources and environment, especially in terms of water resources. In particular, it is an order of magnitude higher than the water resource consumption of any other town. However, it is the center of Jingjiang, which covers $15.37 \%$ of Jingjiang's area and $30.70 \%$ of its population, and it is the township with the largest area and highest population in Jingjiang. Similarly, most industries are concentrated in the Jingcheng Subdistrict. This inevitably leads to a high consumption of resources and a high environmental impact, which corresponds to a high output value. This is the reason why its GDP is much higher than the other towns (it is an order of magnitude higher than the GDP of the other towns). From the perspective of the resource and environment consumption per unit of GDP, the Jingcheng Subdistrict consumes the least, except for water resources per unit of GDP. According to the calculation formula of the resource and environment consumption per unit of GDP, although the resource and environment consumption of Jingcheng is higher than that of the other towns, the GDP of Jingcheng is larger than the total GDP of other towns and one order of magnitude higher than the GDP of other towns. Therefore, the resource and environment per unit of GDP consumption must be very low. This means that its industrial development model is intensive at the present time, but it has a high demand for water resources. Therefore, upgrading the industries themselves can be considered to reduce the water resource consumption and reuse the water resources, or the industrial layout among the different regions can be optimized. The results also show that the industrial development model of Gushan Town is the most extensive because it consumes the most resources (including land and water) per unit of GDP and the third most water environment per unit of GDP. This indicates that the industries' high resources consumption and the pollution emissions do not yield a high output value. To some extent, these industries may be associated with backward production capacities; hence, its industrial structure needs to be adjusted, and some industries should be withdrawn. In terms of details, Gushan Town and Maqiao Town have the first level of water resource consumption per unit of GDP. The two towns have similar water resource consumption per unit of GDP, but Gushan Town consumes six times the amount of water resources consumed by Maqiao Town, and the GDP of Gushan Town is almost double of Maqiao Town.
This shows that the industries of Gushan Town consume excessive water resources without yielding great benefits; thus, its industrial development model needs to be optimized. The industrial development models of Xieqiao Town and Dongqiao Town are relatively intensive because their resources and environment per unit of GDP are at the third or fourth levels, respectively, and they have a high GDP. Therefore, their industrial structure does not need to be adjusted, or it can be partially upgraded and optimized according to their needs within a period of time.

Therefore, the final output value resulting from the industrial layout and structure should be considered comprehensively. A higher resource and environment consumption per unit of GDP indicates that the industrial development model of the towns is extensive or there are certain problems in their industrial development model. The optimization of the regional industrial layout can change the effect of the regional industrial structure on the RECC. For example, through the reconfiguration of industries between the subregions under the premise that the regional industrial structure has not changed, the energy-intensive industries are distributed in areas with high RECC, and this can improve the overall regional RECC in a certain period. This is because the self-purification ability of a region with a low RECC has reached or exceeded its limit. If the industries are still in the region, the region's RECC will drop sharply and the overall regional RECC will drop too; however, the available resources and environment of the region with a high RECC are greater. In particular, when considering the environment, the self-purification ability is better. If energyintensive industries are properly reconfigured from the region with a low RECC to a region with a high RECC while not exceeding the carrying capacity of the region with a high RECC, its self-purification capacity will consume most pollutants without affecting its ecological environment. Then, the overall regional RECC should improve over a certain period. The results of analyzing the degree of the resource and environment consumption in each town present problems in the industrial layout. These results also provide a reference for the optimization of the industrial layout and the adjustment of the industrial structure.

4.2. Development Scenario Assumption. According to the abovementioned industrial evaluation results of Jingjiang, different industrial restructuring scenarios were set. In Scenario $A$, RECC in Jingjiang is based on the current model of social and economic development. For Scenario $A$, the 18 industries that were studied continue to develop according to the current industrial model, and the proportion of the output value of each industry remains unchanged and it continues to grow in the development process. In Scenario $B$, the RECC is based on the industrial restructuring of Scenario $A$, which focuses on the leading industries and eliminating industries in the third category (industries to be eliminated) in Table 1. The RECC is based on a certain level of social and economic development. This study assumes that the level of social and economic development remains unchanged under various development scenarios, and it adopts the current 


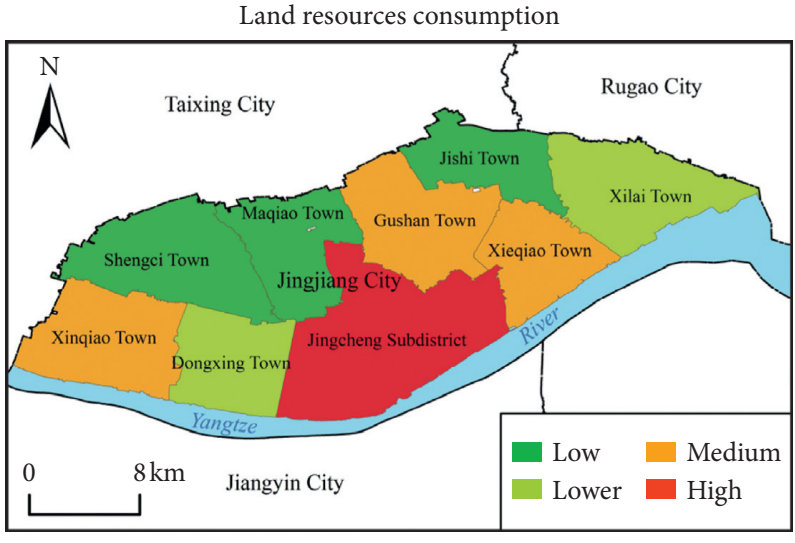

(a)

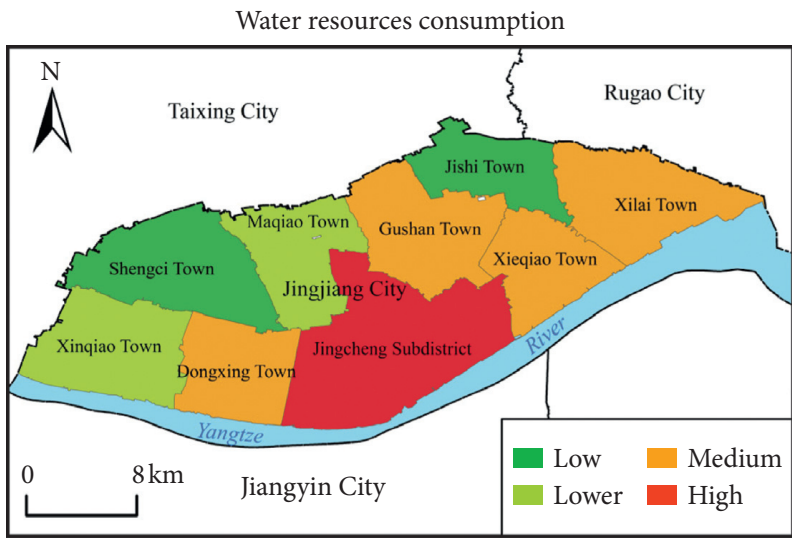

(c)

Water environment consumption

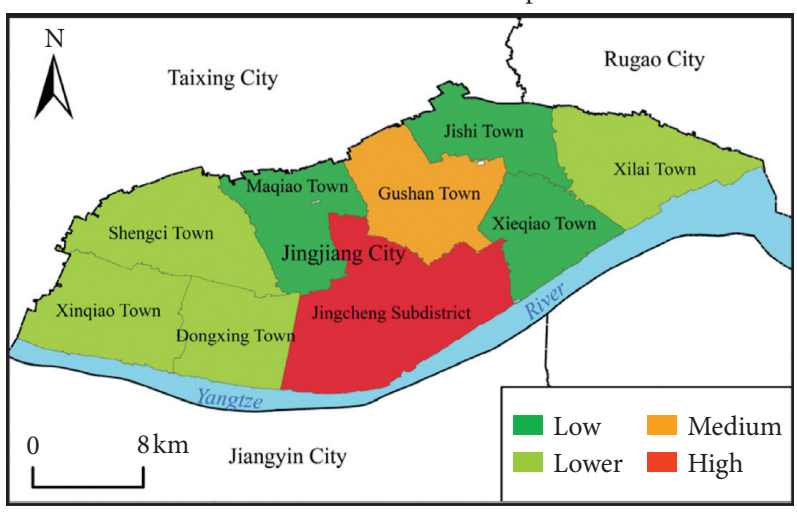

(e)

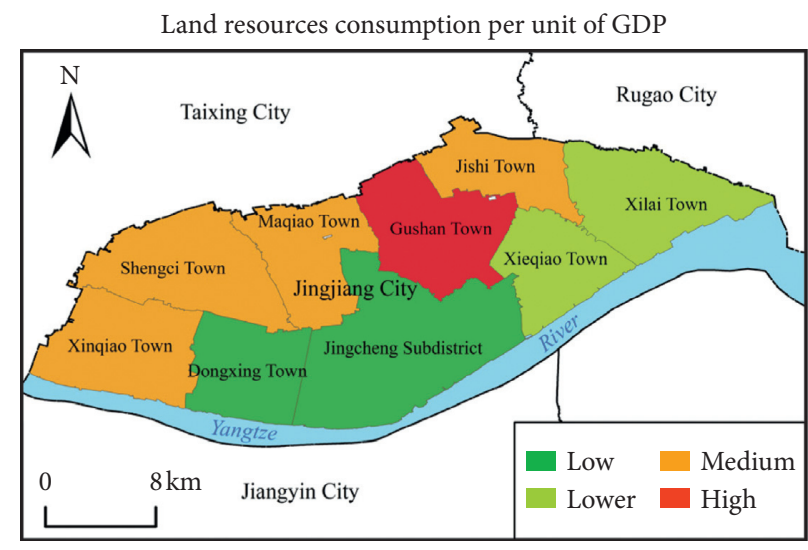

(b)

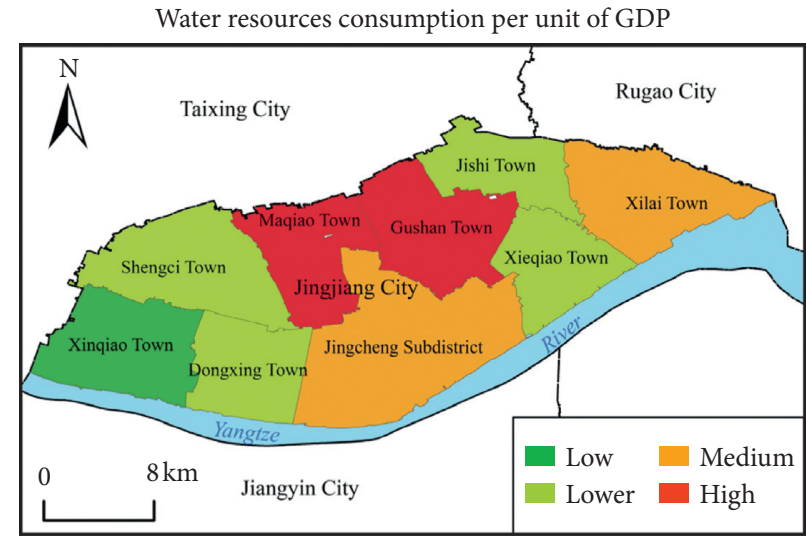

(d)

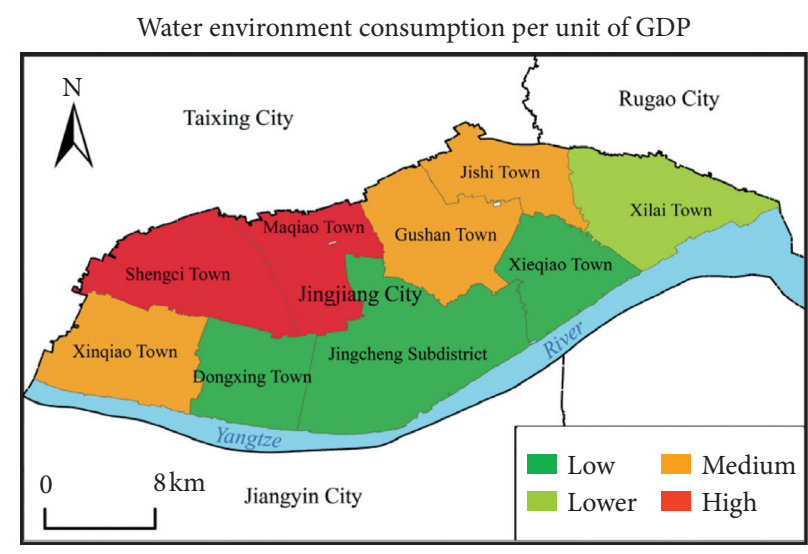

(f)

FIGURE 2: Resource and environment consumption and the resource and environment consumption per unit of GDP for each township.

GDP per capita representation. In Scenario $B$, since the industries to be eliminated are eliminated, the total land resource availability includes the amount of land resources that are saved by the eliminated industries. In other words, this is the sum of the current land resource availability and the land consumption of the eliminated industries. The calculation of the water resource availability and the water environmental capacity is similar to that of the land resource availability.

In addition, the transport and communication facilities industry is currently the industry with the highest output value in Jingjiang, and it is also an industry with a high value of industrial importance in the first category (leading industries). Thus, Scenario $C$ is the RECC with a focus on the development of the transport and communication facilities industry; that is, all the available resources, including the land resource availability, water resource availability, and the water environmental capacity, are used for its development, while other industries remain at the current level.

Similarly, the petroleum, coking, and nuclear fuel processing products industry consumes the least resources per unit of GDP. This includes the land resource availability and 
the water resource availability, and it also consumes the second least water environmental capacity per unit of GDP. Thus, Scenario $D$ is the RECC with the development of the petroleum, coking, and nuclear fuel processing products industry. In Scenario $D$, all the available resources, including the land resource availability, water resource availability, and water environmental capacity are used for its development while other industries remain at the current level.

4.3. Results Analysis of the Development Scenarios. The results of the RECC evaluation for the various development scenarios in Jingjiang are shown in Table 3. The evaluation results show that the land resource carrying capacity is the weakest, the water resource carrying capacity is the strongest, and the water environmental capacity is in the middle for all four development scenarios (Figure 3).

This result shows that the primary factor that restricts the socioeconomic development of Jingjiang is the land resources. Any development scenario is insurmountable because the land resource carrying capacity is based on the remaining construction land. In addition, Jingjiang, as a relatively developed area, has very limited available construction land according to the Adjustment plan for the general plan for land use in Jingjiang City (2006-2020). The analysis also shows that water resources are abundant. Although the total amount of water resources varies from year to year, the annual change is small according to the Taizhou City Water Resources Bulletin; thus, water resources in Jingjiang can support socioeconomic development in terms of the total amount. The water environmental capacity is much lower than the water resource carrying capacity. This indicates that although water resources are abundant, water pollution restricts socioeconomic development under the current emission intensity, which is similar to the case of the land resources.

Some conclusions can be drawn by comparing the various development scenarios. First, the development of leading industries and the elimination of industries to be eliminated (Scenario B) can improve the RECC, which includes the land resource capacity, the water resource capacity, and the water environmental capacity (Figure 4) in comparison to the current development model (Scenario A). The results also indicate that the current industrial development (Scenario $A$ ) has a high demand for the resource and environmental capacity, and industrial restructuring (Scenario $B$ ) has a certain degree of improvement in the utilization efficiency of the resource and environmental capacity. However, the RECC does not improve much, especially in terms of the land resource carrying capacity (Figure 4(a)). Scenario $B$ can improve the RECC in terms of its values. However, eliminating the industries to be eliminated not only affects the diversity of the industrial structure of Jingjiang and its ability to resist risks but also requires hefty financing. For example, the reemployment of the employees from these industries requires a great deal of financing. Therefore, it can be concluded that the improvement in RECC may be unable to make up for the abovementioned financing and risk.
Second, in comparison to Scenario $A$, the use of all the remaining resources to develop the transport and communication facilities industry, with other industries maintaining the current scale of production (Scenario $C$ ), improves the land resource and water environmental capacity (Figures 4(a) and 4(c)). However, the water resource carrying capacity of Scenario $C$ decreases (Figure 4(b)) because the transport and communication facilities industry consumes the most water resources among the 18 industries. It also consumes the second most land resources and emits the third most pollutants (COD) among the 18 industries, which is one of the main reasons that the land resource carrying capacity and the water environmental capacity did not improve much. However, the transport and communication facilities industry is one of the leading industries, and it is currently the industry with the highest output value; thus, its consumption of resources per unit of GDP remains low. In addition, the maximum population and economic volume carried by the resource environment are calculated on the basis of all resources that are used to develop the transport and communication facilities. The output value of the other industries is not included. If the output value of other industries were to be added, the RECC would be greatly improved. Other industries that continue to maintain the current scale of production will either not consume or consume very little land resources; yet, it will consume a certain amount of water resources and emit a certain amount of pollutants. However, water resources are dynamic; thus, the water environmental capacity is also dynamic. These factors will not have too high of an impact; therefore, Jingjiang can consider some extent of development of the transport and communication facilities industry for a certain period, although it does not improve the RECC as much as Scenario B.

Third, in comparison to Scenario $A$, the use of all the remaining resources to develop the petroleum, coking, and nuclear fuel processing products industry, in which the other industries maintain their current scale of production (Scenario $D$ ) improves the RECC. This includes the land resource carrying capacity, the water resource carrying capacity, and the water environmental capacity (Figure 4). Scenario $D$ has the highest RECC among the four scenarios because it consumes the least resources per unit of GDP. Similar to Scenario $C$, RECC can be greatly improved when the output value of the other industries is included. Other industries that continue to maintain the current scale of production will consume a certain amount of resources and the environment. This will not have much of an impact if the consumption of the resources and the environment is controllable. Based on the evaluation results, Jingjiang can prioritize the development of the petroleum, coking, and nuclear fuel processing products industry for a certain period of time.

\section{Discussion}

5.1. Industrial Development Scenarios. The industrial development scenarios presented in this study are based on several assumptions. First, the industrial development 
TABLE 3: Resource environmental carrying capacity (RECC) evaluation in Jingjiang.

\begin{tabular}{|c|c|c|c|c|c|c|c|c|}
\hline \multirow{2}{*}{$\begin{array}{l}\text { Carrying capacity } \\
\text { Subentries }\end{array}$} & \multicolumn{2}{|c|}{ Scenario $A$} & \multicolumn{2}{|c|}{ Scenario $B$} & \multicolumn{2}{|c|}{ Scenario $C$} & \multicolumn{2}{|c|}{ Scenario $D$} \\
\hline & $\begin{array}{l}\text { Population } \\
\text { (thousand) }\end{array}$ & $\begin{array}{l}\text { Economy } \\
\text { (billion) }\end{array}$ & $\begin{array}{l}\text { Population } \\
\text { (thousand) }\end{array}$ & $\begin{array}{l}\text { Economy } \\
\text { (billion) }\end{array}$ & $\begin{array}{l}\text { Population } \\
\text { (thousand) }\end{array}$ & $\begin{array}{c}\text { Economy } \\
\text { (billion) }\end{array}$ & $\begin{array}{l}\text { Population } \\
\text { (thousand) }\end{array}$ & $\begin{array}{c}\text { Economy } \\
\text { (billion) }\end{array}$ \\
\hline $\begin{array}{l}\text { Land resource } \\
\text { carrying capacity }\end{array}$ & 112.05 & 13.08 & 133.33 & 15.56 & 122.33 & 14.28 & 134.44 & 15.69 \\
\hline $\begin{array}{l}\text { Water resource } \\
\text { carrying capacity }\end{array}$ & 7965.88 & 929.64 & 8009.30 & 934.71 & 7779.39 & 907.88 & 9233.34 & 1077.56 \\
\hline $\begin{array}{l}\text { Water } \\
\text { environmental } \\
\text { capacity }\end{array}$ & 209.73 & 24.48 & 217.65 & 25.40 & 213.84 & 24.96 & 220.33 & 25.71 \\
\hline
\end{tabular}

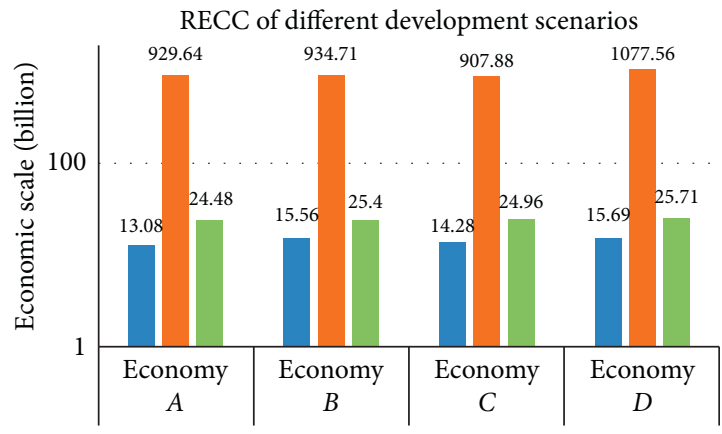

- Land resources carrying capacity

- Water environmental capacity

- Water resources carrying capacity

(a)

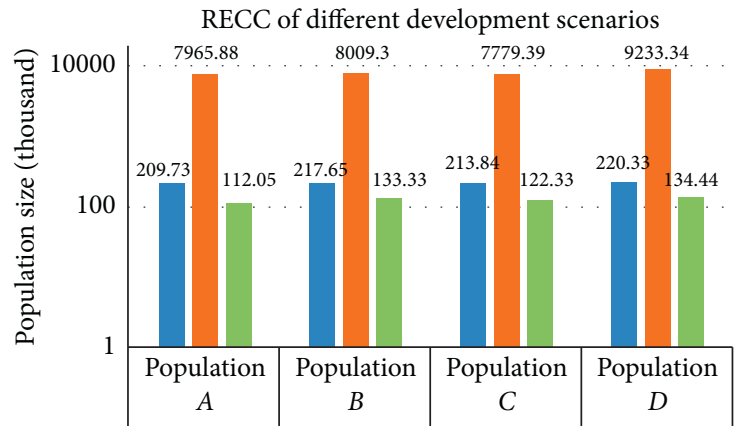

- Land resources carrying capacity

- Water environmental capacity

- Water resources carrying capacity

(b)

Figure 3: RECC of the different development scenarios in Jingjiang.

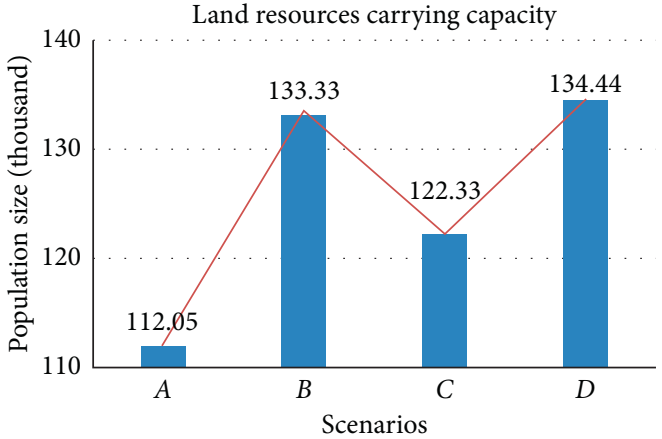

(a)

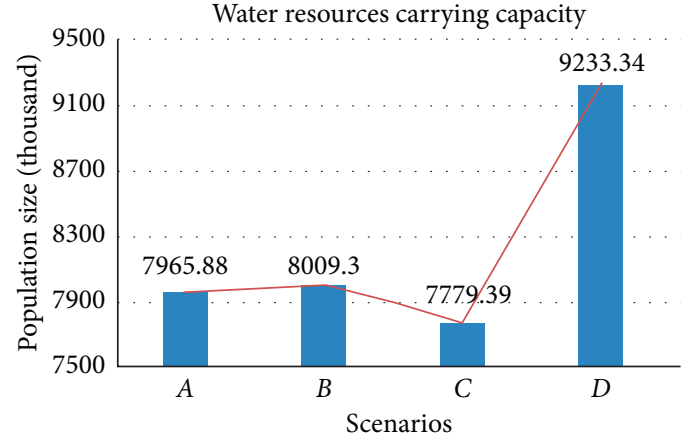

(b)

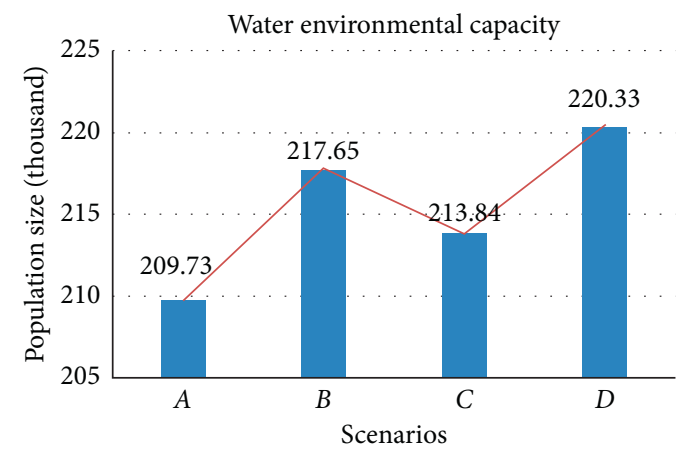

(c)

FIgure 4: Comparison of the RECC under different scenarios in Jingjiang. 
scenarios are based on the current level of socioeconomic development, which means that other socioeconomic development factors remain unchanged as the available resources are used for industrial development. Second, the current per capita GDP representation is adopted, which means that the GDP per capita is constant over the course of industrial development. Third, in the RECC evaluation calculation, the maximum amount of the carrying economy is calculated on the basis of the constant ratio of the output value of each industry to the total output value. In other words, as the available resources support the development of each industry, the output value of each industry continues to increase. Therefore, the total output value also increases; however, the proportion of each industry in the total output value remains unchanged. These assumptions are conducive to the construction of an analytical framework for the relationship between industrial restructuring and RECC, as well as the analysis of the current situation and predicting the research area. Although the research framework in this study is based on these assumptions, it is one of the few studies to link industrial restructuring to RECC.

5.2. Industry Weight. The industry weight is evaluated according to the contribution of a given industry to the regional economic system to identify leading industries, general industries, and industries to be eliminated. The industrial importance evaluation can be oriented toward prioritizing either economic development or resource availability. The evaluation results will be different for different selection angles. The analysis framework constructed in this study aims to evaluate the industrial structure of Jingjiang from multiple perspectives and to explore the correlation between socioeconomic development and the resources and environment, which has a strong policysupporting effect, and it can provide a reference for RECC evaluation research in different regions.

5.3. Industrial Interaction and Scale Effect. Different industries influence each other, and the development of one industry can drive or promote other industries. This study considered the choice of industries in the setting of industrial structure scenarios. For example, Scenario B focuses on developing leading industries, and it eliminates the industries to be eliminated. However, there is an interaction between the industries. For example, the development of leading industries promotes the growth of other industries, and the growth of other industries also promotes the development of leading industries to some extent. Therefore, this is a cyclic process. In some evaluation methods, it is necessary to use a recursive algorithm to simulate this process, which will further complicate the evaluation method. To simplify the method, an algorithm was not adopted in this study; however, more attention is paid to the interaction between the regional industrial structure and the resource environment.

In addition, as a result of the existence of the scale effect, with the increase in the economic scale, the utilization efficiency of the resources will increase, and the ratio of the resource input to the output will decrease. Therefore, the resource utilization intensity and pollution emission intensity of the industries will change in the development process. The scale effect was not considered in this study. To refine the evaluation and improve the accuracy of the evaluation results, it is necessary to identify the resource and environment effects of the industries at different scales in future research.

5.4. Data Acquisition. In this study, a case study was explored for Jingjiang City, and the scope of the analysis was limited by the acquisition of data. However, the size of the resource and environmental capacity is heterogeneous in space, and the different subregions (such as each town) have different socioeconomic systems, which correspond to different resource-related and environmental effects. For example, the total amount of water resources at each township level cannot be obtained with the method that is described in this study; therefore, the maximum population and economy carried by each township's water resources and water environment capacity could not be calculated. As a result, the RECC of each subregion could not be evaluated. In future research, more fine-scale data (such as at the level of each town) can be further obtained to evaluate the RECC of each subregion. Simultaneously, the distribution of land resources, water resources, the population, and the trend of rivers can be combined. In addition, the analytical framework in this study can better assist in realizing the optimized industrial layout. For example, industries in areas with abundant resources and a larger water environmental capacity can be increased, and the ones in areas with greater overloading or pressure on the resources and environment can be reduced. At the same time, the population distribution and employment should also be considered in the industrial layout in order to balance the industrial development, the population employment, and the RECC of each subregion so that sustainable development of the region can be realized. Despite the lack of fine-scale data, this study provides a detailed analysis of the current situation and the problems of resource and environment consumption in each subregion. This reflects the existing problems in the industrial layout, and it plays a guiding role in optimizing the spatial layout.

5.5. Improvement of This Study. This study strengthens the research from the perspective of socioeconomic development, and it constructs an analytical framework of the relationship between industrial restructuring and the RECC. At present, most relevant studies separate the industrial restructuring and RECC. Even if some studies attempt to discuss the two studies together, the industrial restructuring evaluation indicator system and RECC evaluation indicator system are established, respectively, and then, the mutual influence is discussed, but no substantial connection is established. Some other studies just combine the industrial restructuring with one single resource carrying capacity, especially the water resources carrying capacity, which is lack of comprehensiveness. This study is one of the few to 
establish a relationship between the two studies through mathematical models and in-depth discussion of the twoway impact of them. Meanwhile, it analyzes the resource and environment consumption of each subregion to provide support for the optimization of the industrial spatial layout. This is also a rare study combining regional industrial structure and spatial layout status analysis with industrial restructuring simulation. It can further bridge the theoretical research and practical application of RECC, and it can enhance the operability of the research method in the decision support.

\section{Conclusions}

RECC is a typical coupling system for socioeconomic development, resources, and the environment. The composite analysis framework of RECC in this study focuses on the interaction process between the socioeconomic activities and the resources and environment. In other words, the socioeconomic activities are well correlated with the resource consumption and the pollution emissions. Under the condition of limited resources and the environmental capacity, the RECC can be improved by industrial restructuring in order to achieve balance between resource utilization, environmental protection, and economic development. The case of Jingjiang City reveals the current level of resources and the environmental consumption in each subregion and the RECC of the different industrial development scenarios. From the results of the case study, it can be concluded that most of the industries are concentrated in the Jingcheng subdistrict, whose industrial development is presently in an intensive state, and there is room for inter-regional optimization in the future. The use of all the available resources for the development of the petroleum, coking, and nuclear fuel processing products industry, in addition to other industries that are maintained at the current level (Scenario D), can greatly improve the RECC.

There are also some deficiencies in this study. First, the implementation of the analytical framework is based on the assumption of a certain state of economic development. Second, the specific elements were selected according to the characteristics of the research area, but the RECC also involves the ecological carrying capacity and many other factors. Third, some data could not be obtained in this study, such as the total amount of water resources at each township level as mentioned in Section 5.4. Therefore, it is necessary to establish different evaluation subsystems. It is also necessary to actively communicate with the relevant departments and to collect data according to the specific conditions of each region when extending the application of the analytical framework that is proposed in this study to other regions. This will gradually improve the evaluation system while enhancing the universality of the analytical framework.

\section{Data Availability}

(1) The official input-output table of Jiangsu Province 2012 data used to support the findings of this study were supplied by the Jiangsu Provincial Bureau of Statistics under license and so cannot be made freely available. Requests for access to these data should be made to the Jiangsu Provincial Bureau of Statistics, 145 Hanzhongmen Street, Jianye District, Nanjing City, Jiangsu Province, China. (2) The China City Statistical Yearbook 2017 data used to support the findings of this study were supplied by the National Bureau of Statistics under license and so cannot be made freely available. Requests for access to these data should be made to the National Bureau of Statistics, 57 Yuetan South Street, Xicheng district, Beijing, China. (3) The Taizhou City Water Resources Bulletin 2016 data used to support the findings of this study were supplied by the Taizhou Water Conservancy Bureau under license and so cannot be made freely available. Requests for access to these data should be made to the Taizhou Water Conservancy Bureau, No. 309 south hailing road, Hailing district, Taizhou City, Jiangsu Province, China. (4) The Jingjiang Statistical Yearbook 2016 data used to support the findings of this study were supplied by the Jingjiang statistics bureau under license and so cannot be made freely available. Requests for access to these data should be made to the Jingjiang statistics bureau, 1 Yangguang Road, Jingjiang City, Jiangsu Province, China. (5) The adjustment plan for the general plan for land use in Jingjiang City (2006-2020) and survey data of industrial land use in Jingjiang City (2016) data used to support the findings of this study were supplied by the Jingjiang Natural Resources and Planning Bureau under license and so cannot be made freely available. Requests for access to these data should be made to the Jingjiang Natural Resources and Planning Bureau, 12 Yangguang Road, Jingjiang City, Jiangsu Province, China.

\section{Conflicts of Interest}

The authors declare no conflicts of interest.

\section{Authors' Contributions}

Conceptualization was carried out by Y. B. and F. N.; data curation was performed by Y. B. and Y. H.; formal analysis was conducted by $\mathrm{Y}$. B. and X. X.; funding was acquired by F. N.; F. N., Y. B., and Y. H. were responsible for the methodology; project administration was performed by $\mathrm{F}$. N. and Y. B.; supervision was conducted by F. N. and Y. B.; Y. B. and Y. H. wrote the original draft; and Y. B., Y. H., and F. N performed the review and editing. All authors have read and agreed to the published version of the manuscript.

\section{Acknowledgments}

Students from the College of Geography at Nanjing Normal University contributed to the collection of surveyed data and to the construction of a database. The authors would like to express their sincere thanks to all of these students. The authors also would like to thank Editage (http://www. editage.com) for English language editing. This research was funded by the Strategic Priority Research Program of the Chinese Academy of Sciences, No. XDA19040401, and the 
National Key Research and Development Program, No. 2016YFC0503506.

\section{References}

[1] S. Cilliers, M. Du Toit, J. Cilliers, E. Drewes, and F. Retief, "Sustainable urban landscapes: south African perspectives on transdisciplinary possibilities," Landscape and Urban Planning, vol. 125, pp. 260-270, 2014.

[2] W. Liang and M. Yang, "Urbanization, economic growth and environmental pollution: evidence from China," Sustainable Computing: Informatics and Systems, vol. 21, pp. 1-9, 2019.

[3] A. W. Hosmer, E. J. Ijjasz, and G. Fairweather, "Emerging latin American oil spill regulation," in Proceedings of the International Oil Spill Conference, pp. 447-451, Washington, DC, USA, March 1991.

[4] G. Alan, "Third world cities: poverty, employment, gender roles and the environment during a time of restructuring," Urban Studies, vol. 31, no. 4-5, pp. 605-633, 1994.

[5] A. Gill, K. K. Viswanathan, and S. Hassan, "The environmental kuznets curve (EKC) and the environmental problem of the day," Renewable and Sustainable Energy Reviews, vol. 81, no. 2, pp. 1636-1642, 2018.

[6] K. L. White, "Political arithmetick," New England Journal of Medicine, vol. 300, no. 10, pp. 555-556, 1979.

[7] C. Clark, The Conditions of Economic Progress, Macmillan \& Co. Ltd, London, UK, 1940.

[8] K. Simon, "Quantitative aspects of the economic growth of nations: II, industrial distribution of national product and labour force," Economic Development and Cultural Change, vol. 5, pp. 1-11, 1957.

[9] M. Tran, "Modeling sustainability transitions on complex networks," Complexity, vol. 19, no. 5, pp. 8-22, 2014.

[10] Z. Zheng, "Research of potential population carrying capacity of Chinese land," Chinese Geographical Science, vol. 10, no. 5, pp. 33-38, 1996.

[11] A. Dang, S. Yan, H. Wu, and Y. Liu, "A gis based study on the potential land productivity of China," Acta Ecologica Sinica, vol. 20, no. 6, pp. 910-915, 2000.

[12] Z. Feng, Y. Yang, and Z. You, "Research on land resources restriction on population distribution in China, 2000-2010," Geographical Research, vol. 33, no. 8, pp. 1395-1405, 2014.

[13] S. Li, Z. Ying, H. Zhang, G. Ge, and Q. Liu, "Comprehensive assessment of urbanization coordination: a case study of jiangxi province, China," Chinese Geographical Science, vol. 29, no. 3, pp. 488-502, 2019.

[14] Y. Shi and Y. Qu, The Carrying Capacity of Water Resources and its Reasonable Use of Urumqi River, Science Press, Beijing, China, 1992.

[15] Y. Chen and J. Han, "Correlation analysis on water resources utilization and the sustainable development of economy in minqin of Gansu province," Journal of Chemical \& Pharmaceutical Research, vol. 6, no. 4, pp. 157-161, 2014.

[16] Z. Feng and D. Liu, "A study on water resources carrying capacity in Jingjinji Region," Journal of Natural Resources and Development, vol. 21, no. 5, pp. 689-699, 2006.

[17] W. Gao, Y. Zeng, D. Zhao, B. Wu, and Z. Ren, "Land cover changes and drivers in the water source area of the middle route of the south-to-north water diversion project in China from 2000 to 2015," Chinese Geographical Science, vol. 30, no. 1, pp. 115-126, 2020.

[18] Q. Xu, "An exploration of several problems about the analysis of regional mineral resources carrying capacity," Journal of
Natural Resources and Development, vol. 11, no. 2, pp. 135140, 1996.

[19] D. Xu and Y. Wang, "Plume footprints analysis for determining the bearing capacity of atmospheric environment," Acta Scientiarum Polonorum Formatio Circumiectus, vol. 33, no. 6, pp. 1734-1740, 2013.

[20] W. Zeng, W. Yang, R. Chen, and F. Li, "Application of environmental carrying capacity in environmental impact assessment in planning," Chinese Journal of Population Resources and Environment, vol. 17, no. 6, pp. 27-31, 2007.

[21] L. Chen, C. Ren, B. Zhang, L. Li, Z. Wang, and K. Song, "Spatiotemporal dynamics of coastal wetlands and reclamation in the yangtze estuary during past 50 years (1960s-2015)," Chinese Geographical Science, vol. 28, no. 3, pp. 386-399, 2018.

[22] Y. Qi, "The present situation of resource environmental bearing- capacity research and analysis of its main problems," Natural Resources Economic China, vol. 18, no. 5, pp. 7-11+46, 2005.

[23] J. Yang, X. Luo, C. Jin, X. Xiao, and J. Xia, “Spatiotemporal patterns of vegetation phenology along the urban-rural gradient in coastal dalian, China," Urban Forestry \&Urban Greening, vol. 54, Article ID 126784, 2020.

[24] F. Q. Qin, L. F. Wang, and S. F. Shao, "Emergy comparison of typical coastal urban ecosystems in China," Complexity, vol. 2020, Article ID 8071242, 7 pages, 2020.

[25] J. Yin, W. Li, D. Wang, and S. Liu, "Optimization of rural settlement distributions based on the ecological security pattern: a case study of da'an city in Jilin province of China," Chinese Geographical Science, vol. 30, no. 5, pp. 824-838, 2020.

[26] Z. Feng, Y. Yang, and H. Yan, "A review of resources and environment carrying capacity research since the $20^{\text {th }}$ century: from theory to practice," Journal of Research in Science Teaching, vol. 39, no. 3, pp. 379-395, 2017.

[27] J. Yang, Y. Wang, C. Xiu et al., "Optimizing local climate zones to mitigate urban heat island effect in human settlements," Journal of Cleaner Production, vol. 275, Article ID 123767, 2020.

[28] I. Bowen, Population, Cambridge University Press, Cambridge, UK, 1954.

[29] T. R. Malthus, "An essay on the principle of population," Forum for Modern Language Studies, vol. 41, no. 1, pp. 114-115, 2005.

[30] I. Seidl and C. A. Tisdell, "Carrying capacity reconsidered: from malthus' population theory to cultural carrying capacity," Ecological Economics, vol. 31, no. 3, pp. 395-408, 1999.

[31] F. Niu, Z. Feng, and H. Liu, "A review on evaluating methods of regional resources and environment carrying capacity," Journal of Research in Science Teaching, vol. 40, no. 4, pp. 655-663, 2018.

[32] P. L. Errington, "Vulnerability of bob-white populations to predation,” Ecology, vol. 15, no. 2, pp. 110-127, 1934.

[33] L. Zhang, X. Li, W. Li, W. Wang, and X. Liu, "Human carrying capacity research: dilemma and reasons," Acta Ecologica Sinica, vol. 29, no. 2, pp. 889-897, 2009.

[34] J. Yang, A. Guo, Y. Li, Y. Zhang, and X. Li, "Simulation of landscape spatial layout evolution in rural-urban fringe areas: a case study of Ganjingzi district," GIScience \& Remote Sensing, vol. 56, no. 3, pp. 388-405, 2019.

[35] J. Peng, Y. Du, Y. Liu, and X. Hu, "How to assess urban development potential in mountain areas? an approach of ecological carrying capacity in the view of coupled human and natural systems," Ecological Indicators, vol. 60, pp. 1017-1030, 2016. 
[36] Q. Hao, L. Deng, and Z. Feng, "Carrying capacity reconsidered in spatial planning: concepts, methods and applications," Journal of Natural Resources and Development, vol. 34, no. 10, pp. 2073-2086, 2019.

[37] F. Niu, Z. Feng, and L. Hui, "Evaluation of resources environmental carrying capacity and its application in industrial restructuring in Tibet, China," Acta Geographica Sinica, vol. 74, no. 8, pp. 1563-1575, 2019.

[38] X.-Y. Zhou, K. Lei, W. Meng, and S.-T. Khu, "Industrial structural upgrading and spatial optimization based on water environment carrying capacity," Journal of Cleaner Production, vol. 165, pp. 1462-1472, 2017.

[39] W. W. Leontief, Structure of American Economy, 1919-1929, Harward University Press, Cambridge, UK, 1941.

[40] C. Yan, J. Liu, H. Li et al., "Choice of leading industry of agroproduct processing in Hebei province based on improved industrial linkage analysis," Transactions of the Chinese Society of Agricultural Engineering, vol. 34, no. 11, pp. 268-277, 2018.

[41] Y. Ma, Y. Wu, and B. Wu, "Comprehensive evaluation of sustainable urban development of Yangtze river delta based on entropy method and quadrant method," Economic Geography, vol. 35, no. 6, pp. 47-53, 2015.

[42] P. Zhang, D. Yang, E. Li, and Y. Li, “The coupled coordination relationship between land urbanization and population urbanization-a case study of the central plains economic region," Economic Geography, vol. 37, no. 8, pp. 145-154, 2017.

[43] Ministry of Ecology and Environment of the People's Republic of China, Environmental Quality Standards for Surface Water (GB 3838-2002), Ministry of Ecology and Environment of the People's Republic of China, Beijing, China, 2002. 